\title{
Efek Ekstrak Daun Gendola (Basella rubra L.) Terhadap Kadar Kolesterol Darah Tikus Putih yang Diinduksi Alloxan
}

\section{The Effect of Leaf extract of Gendola (Basella rubra L.) on Blood Cholesterol in Albino Rats Induced with Alloxan}

\author{
Nida Fahima Amatullah ${ }^{1 *}$, Nurmawati Fatimah ${ }^{2}$, Bambang Herwanto ${ }^{3}$ \\ ${ }^{1}$ School of Medicine, ${ }^{2}$ Department of Pharmacology, ${ }^{3}$ Department of Cardiovascular, \\ Faculty of Medicine, Universitas Airlangga, \\ Jalan Prof. Mayjen Dr. Moestopo 47 Surabaya, Indonesia \\ *Corresponding author: nidafahima99@gmail.com
}

\begin{abstract}
Abstrak
Studi ini bertujuan menguji perbedaan efek dari ekstrak tanaman gendola terhadap tikus putih yang telah mengalami hyperlipidemia akibat injeksi alloxan. Tikus dibagi ke dalam lima kelompok perlakuan, yakni perlakuan kontrol injeksi alloxan tanpa terapi, tiga perlakuan ekstrak daun gondola, dan satu perlakuan terapi menggunakan Simvastatin. Sampel darah diambil dan kemudian diproses melalui BS-300 Analyzer yang selanjutnya di uji dengan Uji Anova. Dari studi ini, didapatkan hasil bahwa kelima variabel tidak menunjukkan perbedaan hasil penurunan kolesterol yang signifikan. Dapat disimpulkan terapi ekstrak daun gendola tidak memberikan efek penurunan kadar kolesterol.
\end{abstract}

Kata kunci: gendola, kolesterol, tikus putih, alloxan

\section{Abstract}

This study aimed to determine the different effects of gendola's leaves extract in albino rats that was previously induced with alloxan resulting to hyperlipidemia. A total of 30 albino rats were used in this study examined various dosage and comparing them to the massively used and known pharmacy, Simvastatin. The blood sample taken from albino rats examined through BS-300 Analyzer and proceed with Anova test. The result showed that all treatment groups didn't show significant differences on decreasing cholesterol level. Therefore, it can be concluded that gendola leaves extract therapy was not alleviate on cholesterol level.

Key words: Basella rubra L, cholesterol, albino rat, alloxan

Received: 5 September 2019

Revised: 30 September 2019

Accepted: 21 Oktober 2019

\section{PENDAHULUAN}

Hiperkolesterolemia adalah kondisi dimana kadar kolesterik dalam tubuh mengalami kenaikan sehingga berada di atas ambang normal. Kondisi hiperkolesterolemia terbagi lagi menjadi dua kondisi, yaitu disebabkan oleh hiperlipidemia dan hiperlipoproteinemia. Tingginya kadar kolesterol dalam tubuh merupakan pemicu terbesar berbagai gangguan jantung. Satu dari tiga pengidap ischaemic heart disease akibat dari atherosclerosis yang dipicu oleh karena hiperkolesterolemia (Huxley dan Lewington, 2002).
Menurut World Health Organization (WHO), peningkatan kadar kolesterol diperkirakan mengakibatkan 2.6 juta kematian (total $4.5 \%$ ) dan 29.7 juta penurunan umur hidup setiap tahunnya. Menurut WHO, penyebaran kasus ini juga bervariasi menurut tingkat ekonomi negara masing-masing. Populasi pada negara berpenghasilan rendah menunjukkan data bahwa satu dari empat orang dewasa mengidap kenaikan total kolesterol. Pada Negara berpenghasilan menengah kebawah, terdapat peningkatan kadar kolesterol pada sepertiga orang dewasa. Sedangkan pada negara berpenghasilan tinggi, kasus ini terdapat pada separuh orang dewasa (WHO, 2018). 
Meskipun beresiko mengakibatkan kematian, hiperkolesterolemia dapat dicegah dan ditangani agar terhindar dari komplikasi dengan berbagai upaya, diantaranya dengan diet dan berbagai jenis upaya pengobatan (Mannu et al., 2013).

Tradisi membudidayakan tanaman obat membuat pengobatan tradisional kembali dilirik seiring dengan adanya gerakan back to nature yang sedang marak secara global. Tidak hanya di Indonesia, penggunaan obat tradisional juga banyak diminati di Negara lain. Di Cina, 90\% penduduk mempercayakan pengobatan tradisional sebagai sarana kesehatan. Di Jepang, angka tersebut mencapai 70\%. Di Amerika 40\% penduduk telah terakses dengan pengobatan tradisional. Di Indonesia sendiri baru 20\% masyarakat yang memanfaatkan pengobatan tradisional (Riset Kesehatan Dasar, 2013).

Pengobatan tradisional diminati karena bahan-bahannya mudah didapat. Budaya pengobatan tradisional hingga kini masih dilestarikan di kalangan urban dengan istilah yang lebih akrab, jamu (Suparmi dan Wulandari, 2012.

Masyarakat telah membudidayakan beberapa tanaman yang dipercaya dapat menjadi obat alternatif dalam penanganan hiperlipidemia. Salah satu tanaman yang telah terkenal di kalangan tenaga pengobatan tradisional adalah tanaman gendola (Basella rubra Linn).

Gendola dikenal memiliki berbagai khasiat yang membuatnya menjadi obat tradisional pilihan masyarakat. Penduduk pulau Jawa telah lama memanfaatkannya untuk berbagai proses penyembuhan penyakit seperti penyembuh luka, memulihkan tenaga ibu setelah bersalin dan lain sebagainya. Gendola juga dapat digunakan untuk pemulihan demam tifoid, radang usus, asam urat, disentri, dan wasir. Bagian dari tanaman ini yang dimanfaatkan biasanya adalah bagian akar dan daun (Joni et al., 2017)

Gendola mengandung flavonoid (Setiaji, 2009) yang berkhasiat untuk mengurangi kadar kolesterol dalam tubuh. Atas dasar ini, dipilihlah ekstrak daun gendola dalam uji penurunan kadar kolesterol sebagai subjek dalam penelitian ini.

\section{METODE PENELITIAN}

\section{Jenis dan Rancangan Penelitian}

Penelitian ini menetapkan metode eksperimental, dan bertujuan untuk menentukan adanya pengaruh ekstrak etanol daun gendola. terhadap tikus putih (Rattus norvegicus) yang mengalami kondisi hyperlipidemia.

Rancangan penelitian ini menggunakan rancangan post-test only control group design, dengan merandomisasi sampel tikus dalam 5 kelompok. Diantara 5 kelompok tersebut, terdapat kelompok kontrol dan eksprimental. Pada kelima kelompok ini nantinya akan dilakukan post-test sebagai indikator keberhasilan dari pengobatan yang sedang dilakukan.

Populasi yang akan diteliti pada penelitian ini adalah tikus putih (Rattus Norvegicus). Penelitian ini menggunakan teknik random sampling sebagai teknik pengambilan sampel, yakni teknik pengambilan sampel secara acak terhadap populasi yang ada, dari Labolatorium Farmakologi Fakultas Kedokteran Universitas Airlangga Surabaya. Pada masa penelitian, hewan coba dikelompokkan dalam kandang masing-masing sesuai variabelnya. Pakan yang diberikan adalah jenis CP 593 dari PT. Charoen Pokphand. Sedangkan minum yang digunkana adalah air PAM ad libitum.

Besar sampel atau jumlah ulangan (replikasi) yang dibutuhkan pada penelitian ini dihitung dengan menggunakan rumus Federer:

$$
\begin{aligned}
& (\mathrm{t}-1)(\mathrm{n}-1)>=15 \\
& \mathrm{t}=\text { jumlah kelompok perlakuan } \\
& \mathrm{n}>=4.75
\end{aligned}
$$

Tikus yang dibutuhkan per kelompoknya adalah 5. Ditambah dengan faktor kematian $10 \%$ yaitu 5.5 dibulatkan menjadi 6. Sehingga dibutuhkan sampel sebanyak minimal 30 ekor untuk perlakuan pemberian alloxan dan ekstrak daun gendola. Namun, dikarenakan kadar kolesterol tikus yang dapat dipakai dibatasi hanya sampai $300 \mathrm{mg} / \mathrm{dL}, 7$ tikus disiapkan untuk kondisi insidental.

Percobaan terhadap daun gendola dengan cara mengekstrak tanaman dengan etanol dan diamati pengaruhnya terhadap lipid-induced 
tikus. Dengan rancangan acak terkontrol dengan menggunakan 30 ekor tikus putih yang dipilih secara random dan dibagi menjadi 5 kelompok yaitu K1 (Kontrol normal), K2 (pemberian alloxan $120 \mathrm{mg} / \mathrm{kgBB}$ ), P1 (pemberian alloxan $120 \mathrm{mg} / \mathrm{kgBB}$ dan diterapi dengan ekstrak etanol daun gendola $400 \mathrm{mg} / \mathrm{kgBB}$ ), P2 (pemberian alloxan $120 \mathrm{mg} / \mathrm{kgBB}$ dan diterapi dengan ekstrak etanol daun gendola $500 \mathrm{mg} / \mathrm{kgBB}$ ), P3 (pemberian alloxan $120 \mathrm{mg} / \mathrm{kgBB}$ dan diterapi dengan ekstrak etanol daun gendola 600 $\mathrm{mg} / \mathrm{kgBB}$ ) dan P4 (pemberian alloxan 120 $\mathrm{mg} / \mathrm{kgBB}$ dan diterapi dengan Simvastatin 0.18 $\mathrm{mg} / \mathrm{hari} / 200 \mathrm{~g} \mathrm{BB}$ ).

Menurut Tandi (2017), ekstrak etanol daun gondola merah berpengaruh terhadap penurunan kadar kreatinin dan ureum tikus diabetes dan dosis $100 \mathrm{mg} / \mathrm{kg}$ BB memberikan pengaruh yang signifikan terhadap penurunan kadar kretainin dan $200 \mathrm{mg} / \mathrm{kg}$ BB memberikan pengaruh penurunan kadar ureum tikus diabetes. Ekstrak etanol daun gondola dosis $400 \mathrm{mg} / \mathrm{kg}$ BB memiliki efek terhadap regenerasi sel pada tubulus ginjal tikus diabetes. Sedangkan Dosis simvastatin pada Rattus norvegicus dikonversi berdasarkan konversi Laurence dan Bacharach (2013) yaitu: $0.18 \mathrm{mg} / \mathrm{hari} / 200 \mathrm{~g}$ BB.

Suspensi Simvastatin diperoleh dengan melarutkan $0.18 \mathrm{mg}$ simvastatin dalam bentuk bubuk ke dalam $1 \mathrm{~mL}$ akuades. Rata-rata berat tikus normal adalah 230 g. Sedangkan untuk tikus dalam keadaan hiperlipidemia akan mengalami kenaikan berat badan sehingga dosis simvastatin yang dibutuhkan juga menyesuaikan berat tikus.

Hewan coba diadaptasikan terlebih dahulu selama 14 hari. diberikan perlakuan pertama (injeksi Alloxan). Pada hari ke 33, dilakukan pengukuran berat badan tikus untuk mengetahui apakah tikus telah mengalami kondisi hyperlipidemia. Setelah itu, isuntikkan ekstrak gendola pada P1 dan P2, P3 dan simvastatin pada P4 di hari ke 34. Prosedur ini terus diulang hingga pada dari ke 54 diukurlah kembali kadar kolesterol tikus-tikus tersebut.

Pengumpulan data dilakukan dengan melalui tes kadar kolestrol darah menggunakan alat $B S$ 300 Analyzer. Teknik analisis data akan dilakukan dengan konfirmasi tentang perbandingan kadar kolesterol dalam darah dengan kadar ekstrak gendola yang diberikan menggunakan uji Saphiro-Wilk dilanjutkan uji Anova.

\section{HASIL DAN PEMBAHASAN}

Setiap liter ekstrak etanol daun gondola mengandung 20-70 mg flavonoid. Flavonoid yang merupakan aglycons derivative, glikosida dan metil masuk secara peroral dan selanjutnya diserap dalam usus. Aglycons diserap dengan bantuan micelle dari garam empedu pada epitelium dinding usus yang kemudian masuk ke aliran darah tubuh. Melalui vena porta, flavonoid akan disalurkan ke liver (Tandi, 2017). Flavonoid dapat digunakan sebagai antiinflammatory agent dikarenakan zat tersebut dapat memodifikasi metabolisme asam arakidonat pada keeping darah. Selain itu, flavonoid juga bekerja dengan cara memblokir jalur cyclooxygenase dan lipooxygenase (Deviana dkk., 2018). Dasar inilah yang melatarbelakangi pemilihan gendola sebagai terapi penurunan kadar kolesterol (Panche et al., 2016).

Data kolesterol total darah yang didapat, diolah untuk mendapatkan hasil analisis deskriptif and inferensial. Analisis inferensial dimulai dengan menggunakan uji normalitas Saphiro-Wilk test karena banyak sampel yang digunakan adalah 42 tikus (kurang dari 50 sampel). Data yang berdistribusi normal, akan dilanjutkan dengan analisis data rasio secara parametrik berupa Oneway Anova dan data yang tidak berdistribusi normal akan diuji dengan menggunakan uji non parametric Kruskal Wallis. Perbedaan yang signifikan pada uji Kruskal Wallis, akan dilanjutkan dengan uji Mann Whitney untuk mengetahui ada tidaknya perbedaan pada masing-masing kelompok.

Berdasarkan ulasan yang ditulis oleh Harini dan Astirin (2009), kadar kolesterol normal tikus putih berkisar antara 10-54 mg/dL. Hal ini menyababkan kesulitan mengukur kadar kolesterol awal tikus menggunakan alat GCU, mengingat alat tersebut hanya dapat membaca 
kadar kolesterol mulai dari $100 \mathrm{mg} / \mathrm{dL}$ atau lebih.

Pengukuran berat badan dilakukan sebelum dilakukan perlakuan simvastatin dan ekstrak etanol daun gondola sebagai indikator bahwa tikus telah mengalami keadaan hyperlipidemia (Gambar 1).

Tabel 1. Hasil pengukuran kolesterol total $(\mathrm{mg} / \mathrm{dL})$ pada semua perlakuan

\begin{tabular}{cc}
\hline Perlakuan & Kadar kolesterol \\
\hline K & $59.6^{\mathrm{a}} \pm 10.4$ \\
P1 & $56.7^{\mathrm{a}} \pm 14.3$ \\
P2 & $60.7^{\mathrm{a}} \pm 17.3$ \\
P3 & $60.6^{\mathrm{a}} \pm 13.4$ \\
P4 & $55.0^{\mathrm{a}} \pm 11.0$
\end{tabular}

Superskrip sama pada kolom yang sama menunjukkan tidak berbeda signifikan $(p>0.05)$

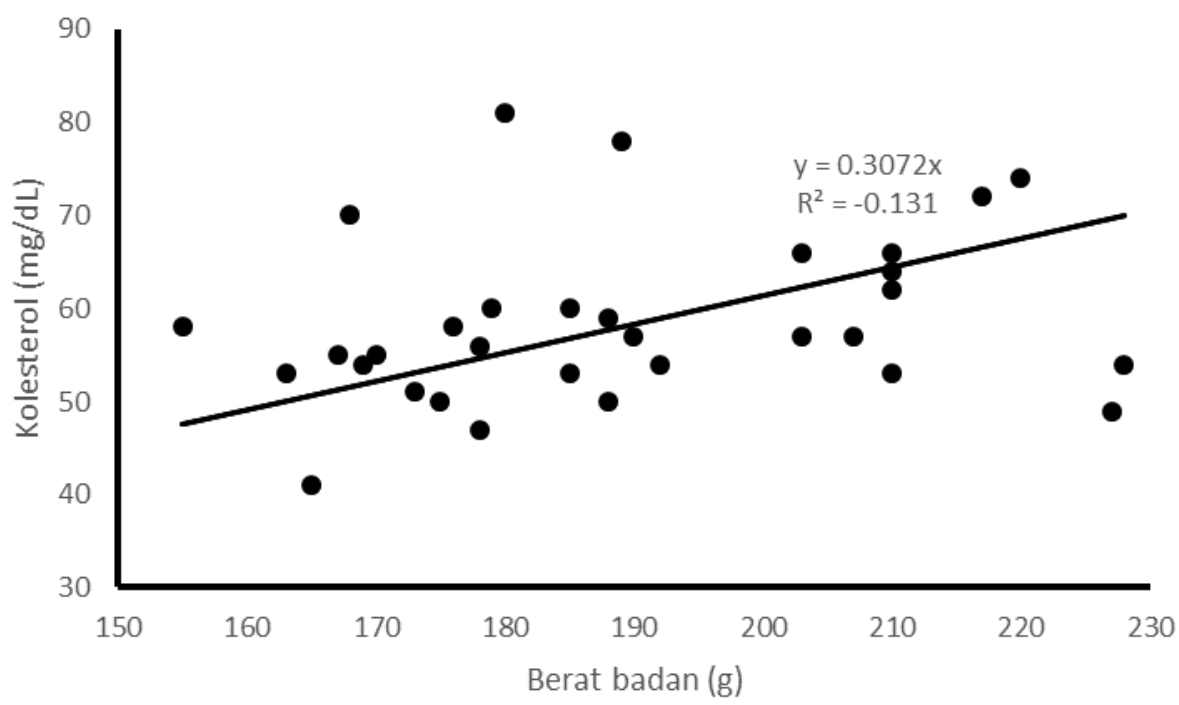

Gambar 1. Hasil korelasi berat badan terhadap kolesterol total pada semua perlakuan

Jumlah sampel pada awal percobaan mulanya berjumlah 35 . Tetapi seiring berjalannya waktu, sampel berkurang menjadi 32 dikarenakan 3 tikus mati di tengah masa percobaan. Dikarenakan sampel percobaan kurang dari 50, maka uji normalitas yang digunakan adalah Saphiro-Wilk test yang menghasilkan nilai $\mathrm{p}$ berbeda tiap kelompoknya. Dari uji normalitas tersebut, didapatkan bahwa data signifikansi kelompok $\mathrm{K}, \mathrm{P} 3$ dan P4 memiliki persebaran data yang normal. Sedangkan P1 dan P2 memiliki distribusi data tidak normal. Karena dari kelima kelompok tersebut terdapat kelompok dengan distribusi tidak normal, maka tahap pengolahan data dilanjutkan dengan uji non-parametrik Kruskal Wallis untuk mengetahui apakah ada perbedaan dari keseluruhan kelompok.
Hasil pengukuran kolesterol total dapat diamati pada Tabel 1. Hasil rerata kadar kolesterol total pada masing masing kelompok adalah $\mathrm{K}$ dengan rata-rata $59.6 \pm 10.4 \mathrm{mg} / \mathrm{dL}$, Kelompok P1 dengan rata-rata $56.7 \pm 14.3 \mathrm{mg} / \mathrm{dL}$, $\mathrm{P} 2$ dengan rata-rata $60.7 \pm 17.3 \mathrm{mg} / \mathrm{dL}, \mathrm{P} 3$ dengan rata-rata $60.6 \pm 13.4 \mathrm{mg} / \mathrm{dL}$, dan $\mathrm{P} 4$ dengan ratarata $55.0 \pm 11.0 \mathrm{mg} / \mathrm{dL}$. Hasil ini kemudian diolah dengan menggunakan uji Kruskal Wallis. Dari hasil perhitungan uji Kruskal Wallis, didapatkan bahwa data dari kelima variable tidak menunjukkan perbedaan yang signifikan. Artinya, perlakuan P1, P2, P3 dan P4 pada tikus tidak menghasilkan efek penyembuhan, dikarenakan tidak adanya perbedaan hasil dengan perlakuan K. Hal ini dikarenakan oleh beberapa faktor mekanisme kerja ekstrak etanol daun gendola tentu berbeda dengan kerja 
simvastatin (Tomás et al., 2000). Berdasarkan beberapa literatur, efek terapi simvastatin lebih baik dibandingkan dengan efek terapi ekstrak etanol daun gendola. Daun gendola memiliki berbagai kandungan, yang tidak seluruhnya memberikan efek terhadap penurunan kadar kolesterol, sehingga diperlukan dosis yang jauh lebih besar agar mendapatkan efek yang sama dengan simvastatin (Lukiati, 2014). Namun, dari percobaan kali ini dibuktikan bahwa perbandingan kadar kolesterol total pada kelompok P1, P2, P3 dan P4 tidak menunjukkan perbedaan signifikan. Faktor diet dan perlakuan awal tikus bisa berkontribusi pada hasil ini. Kadar alloxan yang diberikan bisa jadi melebihi atau kurang dari dosis yang dibutuhkan untuk mengkondisikan tikus dalam keadaan hiperlipidemia, sehingga keempat perilaku tidak menunjukkan perbedaan signifikan.

\section{KESIMPULAN}

Tikus dengan pemberian ekstrak etanol daun gendola menunjukkan perbedaan yang tidak nyata dengan kelompok kontrol terhadap kadar kolesterol total.

\section{UCAPAN TERIMA KASIH}

Terima kasih kepada Laboratorium Farmakolgi Fakultas Kedokteran Universitas Airlangga yang telah memfasilitasi dan membantu sarana prasarana dalam terwujudnya penelitian ini. Terimakasih kepada Alm. Sunarni Zakaria yang telah membimbing dan mengarahkan jalannya penelitian.

\section{DAFTAR PUSTAKA}

Badan Penelitian dan Pengembangan Kesehatan

Kementrian Kesehatan RI. 2013. Riset Kesehatan Dasar 2013. Kementrian Kesehatan RI. Jakarta.

Deviana, D., Cahyo, N.P.D., Kumalaningrum, D.R., Kusuma, W.A., Lailiyah, F., Purnama, M.T.E. 2018. Rekayasa Konsentrat Bekatul dengan Tepung Jantung Pisang Dapat
Meningkatkan Berat Badan dan Menurunkan Kadar Kolesterol Kambing. J. Sain Vet., 36(1), 74-79.

Huxley, R., Lewington, S. 2002. Cholesterol, coronary heart disease and stroke: a review of published evidence from observational studies and randomized controlled trials. Aug, 2(3), 315-23.

Joni, T., Rizki, M., Mariani, R., Alan, F. 2017. Uji Efek Ekstrak Etanol Daun sukun Articarpusaltilis (Parkinson Ex FA Zorm) Terhadap Penurunan Kadar Glukosa Darah, Kolesterol Total Dan Gambaran HistoPatologi Pankreas Tikus Putih Jantan Hiperkolesterolemia-Diabetes. J. Sains Kes., 2303-0267.

Laurence, D.R., Bacharach, A.L. (Eds.). 2013. Evaluation of drug activities: pharmacometrics. Elsevier.

Lukiati, B. 2014. Penentuan Aktivitas Antioksidan Dan Kandungan Fenol Totalekstrak Daun Gendola (Basella Rubra Linn) Dan Daun Binahong (Anredera Cordifolia Stennis) Sebagai Kandidat Obat Herbal. In Proceeding Biology Education Conference: Biology, Science, Enviromental, and Learning, 11(1), 195200).

Mannu, G.S., Zaman, M.J., Gupta, A., Rehman, H.U., Myint, P.K. 2013. Evidence of lifestyle modification in the management of hypercholesterolemia. Curr. Cardiol., Rev., 9(1), 2-14.

Harini, M., Astirin, O.P. 2009. Blood cholesterol levels of hypercholesterolemic rat (Rattus norvegicus) after VCO treatment. Nusantara Biosci., 1(2), 53-58.

Panche, A.N., Diwan, A.D., Chandra, S.R. 2016. Flavonoids: an overview. J. Nutr. Sci., 5, e47. 
Setiaji, A. 2009. Uji Aktivitas Antibakteri Ekstrak Petroleum Eter, Etil, Asetat dan Etanol, 70\% Rhizoma Gendola (Basella rubra Linn (Tenore) Steen) Terhadap Staphylococcus aureus ATCC 25923 dan Escherichia coli ATCC 11229 serta Skrining Fitokimianya. Skripsi. Surakarta: Fakultas Farmasi, Universitas Muhammadiyah Surakarta.

Suparmi, Wulandari, A. 2012. Herbal Nusantara 1001 Ramuan Tradisional Asli Indonesia. Yogyakarta: Andi Offset.

Tandi, J. 2017. Efek Ekstrak Etanol Daun Gendola Merah (Basella alba L.) terhadap Kadar Kreatinin, Ureum dan Deskripsi
Histologis Tubulus Ginjal Tikus. Jurnal Farmasi Galenika. Galenika J. Pharm. Palu.

Tomás, M., Sentí, M., García-Faria, F., Vila, J., Torrents, A., Covas, M., Marrugat, J. 2000. Effect of simvastatin therapy on paraoxonase activity and related lipoproteins in familial hypercholesterolemic patients. Arteriosclerosis, thrombosis, and vascular biology, 20(9), 2113-2119.

World Health Organization. 2008. Global Health Observatory (GHO) data: Raised Cholesterol. 